\title{
Modelling the effects of waste components on cement hydration
}

\author{
R.J. van Eijk and H.J.H. Brouwers \\ University of Twente Department of Civil Engineering and Management, \\ P.O. Box 217, 7500 AE Enschede, The Netherlands
}

Ordinary Portland Cement (OPC) is often used for the Solidification/Stabilization (S/S) of waste containing heavy metals and salts. These waste componenents will precipitate in the form of insoluble compounds onto unreacted cement clinker grains preventing further hydration. In this study the long term effects of the presence of contaminants in solidified waste is examined by numerically simulating cement hydration after precipitation of metal salts on the surface of cement grains. A cement hydration model was extended in order to describe porewater composition and the effects of coating. Calculations were made and the strength development predicted by the model was found to agree qualitatively with experimental results found in literature. The complete model is useful in predicting the strength and leaching resistance of solidified products and developing solidification recipes based on cement.

\section{INTRODUCTION}

Ordinary Portland Cement (OPC) is often used for the Solidification/Stabilization (S/S) of waste. Waste components can retard or even stop the hydration of cement by precipitation of insoluble compounds on the partly hydrated cement particles [1]. Yousuf et al. [2] describe a "Charge Dispersal Model" in which zinc hydroxide anions are dispersed by the presence of $\mathrm{OH}^{-}$ions in the cement porewater. Because the negative cement surface is chargecompensated by $\mathrm{Ca}^{2+}$ ions, a diffuse layer of negative zinc hydroxide anions is present and will be transformed into calcium zincate which completely coats the cement particles with an impermeable layer and thus inhibits further hydration reactions. Experiments with cadmium and lead showed that coating took place in the first minutes after mixing cement, water and waste [3].

This coating mechanism can be modelled using a cement hydration computer model that was developed at NIST [4]. In this model a hydrating cement paste is represented by a digital matrix of pixels with a unit size of $1 \mathrm{~m}^{3}$, which are assigned to water, gypsum or one of the cement mineral phases or possible reaction products. A simulation consist of dissolution cycles in which solid phases are scanned and can dissolve, react, diffuse and precipitate as $\mathrm{CH}$ or calcium-silicate hydrate (CSH). After a large number of hydration cycles it predicts the hydration degree, the porosity and the phase composition of the solid structure. In order to simulate cement hydration in the presence of waste components, it is important to consider the porewater composition. The chemical equilibria of interest are strongly 
dependent on the presence of common ions in cement porewater such as $\mathrm{Ca}^{2+}, \mathrm{K}^{+}, \mathrm{Na}^{+}$and $\mathrm{OH}^{-}$. Based on these equilibria, the $\mathrm{pH}$ and the amount of precipitate can be determined.

\section{POREWATER CONCENTRATIONS}

The pore solution is assumed to be saturated in $\mathrm{Ca}(\mathrm{OH})_{2}$ during cement hydration. During cement hydration high amounts of alkalis, sodium and potassium, are released. While the ion products of both $\mathrm{KOH}$ and $\mathrm{NaOH}$ are significantly higher compared to that of $\mathrm{Ca}(\mathrm{OH})_{2}$, it is assumed that the solution is always saturated with regard to the latter. Thus, given the total concentration of alkali released (sum of $\mathrm{Na}^{+}$and $\mathrm{K}^{+}$) into the porewater and the known ion product for $\mathrm{Ca}(\mathrm{OH})_{2}$ it is possible to calculate $\left[\mathrm{OH}^{-}\right]$and $\left[\mathrm{Ca}^{2+}\right]$ concentrations as a function of hydration degree.

Taylor [5] developed a method to describe the alkali content in cement pore water. It is based on the total alkali content in cement, the w/c ratio used and the hydration degree. When the release and uptake of alkalis and the porosity fraction is known, the concentration of alkalis and corresponding $\mathrm{OH}^{-}$can be predicted during hydration.

For most Portland cements the $\mathrm{Na}_{2} \mathrm{O}$ equivalent is given, which is the mass percentage of $\mathrm{Na}_{2} \mathrm{O}$ that would produces the same amount of moles of alkali as the sum of $\mathrm{Na}_{2} \mathrm{O}$ and $\mathrm{K}_{2} \mathrm{O}$ mass present in cement. All calculations will be based on this equivalent as if the amount of alkali released only consists of $\mathrm{Na}^{+}$.

The total number of moles of alkalis per gram cement is:

$$
N a_{T}=\frac{N a_{e q} \cdot 2}{M_{N a_{2} O}}
$$

$\mathrm{Na}_{\mathrm{T}}=$ alkali content in [mole/g]

$\mathrm{Na}_{\text {eq }}=\mathrm{Na}_{2} \mathrm{O}$ equivalent $[\mathrm{g} / \mathrm{g}]$

$\mathrm{M}_{\mathrm{Na} 2 \mathrm{O}}=$ molecular mass $\mathrm{Na}_{2} \mathrm{O}=62[\mathrm{~g} / \mathrm{mole}]$

Assuming that alkalis are released linearly proportional with hydration degree, the total alkali concentration released in the pore solution, is calculated as follows:

$$
\left[N a^{+}\right]_{\text {released }}=\frac{N a_{T} \cdot \alpha \cdot m_{c}}{\frac{\phi_{p o r}}{\phi_{p o r}^{0}} \cdot \frac{m_{w}}{\rho_{w}}}=\frac{N a_{T} \cdot \alpha}{\frac{\phi_{p o r}}{\phi_{p o r}^{0}} \cdot w / c} \cdot \rho_{w}
$$

$\left[\mathrm{Na}^{+}\right]=$alkali released in $[$mole/l]

$\alpha=$ hydration degree

$\mathrm{m}_{\mathrm{c}}=$ mass cement in $[\mathrm{g}]$

$\mathrm{m}_{\mathrm{w}}=$ mass water in $[\mathrm{g}]$ 


$$
\begin{aligned}
\frac{\phi_{p o r}}{\phi_{p o r}^{0}} & =\text { concentration factor } \\
\mathrm{w} & =\text { water density }=1000\left[\mathrm{~g} / \mathrm{dm}^{3}\right] \\
\mathrm{w} / \mathrm{c} & =\text { water/cement ratio }
\end{aligned}
$$

The concentration factor, defined as the ratio of the porosity fraction to the initial porosity fraction is used to account for the decrease in porosity during hydration and is therefore $\alpha$ dependent. As a result of this decrease in porosity all ions present in the pore solution are concentrated correspondingly. In Taylor [5] it is discussed that the amount of each alkali cation taken up by the hydration products $\mathrm{CSH}$ and $\mathrm{AFm}$ phase is proportional to the concentration present in the solution and the quantity of these hydration products formed. All alkalis are both released and consumed with equivalent amounts of $\mathrm{OH}^{-}$ions. Taylor introduced two empirical constants, called binding factors, which are numerically equal to the amount of alkali in mmole that can be taken up from a $1 \mathrm{M}$ alkali solution by the total quantity of hydration products formed from $100 \mathrm{~g}$ OPC. Although the consumption rates for $\mathrm{Na}^{+}$and $\mathrm{K}^{+}$will not be exactly the same an estimated mean value of 0.23 mmole alkali per $\mathrm{g}$ OPC per mole alkali per liter porewater will be used here. Hence the amount of alkalis consumed in mole/l is:

$$
\left[N a^{+}\right]_{\text {consumed }}=\frac{b_{N a} \cdot \alpha \cdot m_{c} \cdot\left[N a^{+}\right]_{\text {released }}}{m_{w}}=\frac{b_{N a} \cdot \alpha}{w / c} \cdot\left[N a^{+}\right]_{\text {released }}=\frac{b_{N a} \cdot N a_{T} \cdot \rho_{w} \cdot \alpha^{2}}{\frac{\varphi_{\text {por }}}{\varphi_{\text {por }}} \cdot(w / c)^{2}}
$$

$\mathrm{b}_{\mathrm{Na}}=$ alkali binding factor $=0.23[\mathrm{ml} / \mathrm{g}]$

The difference between the amounts of alkali released and consumed gives actual alkali pore concentration.

$$
\left[\mathrm{Na}^{+}\right]=\left[\mathrm{Na}^{+}\right]_{\text {released }}-\left[\mathrm{Na}^{+}\right]_{\text {consumed }}
$$

The pore solution is saturated with respect to $\mathrm{CH}$. The corresponding activity product was taken from SOLTEQ [6], the chemical equilibrium model developed by Batchelor and $\mathrm{Wu}$, based on MINTEQA2 [7]. The corresponding activity coefficients were calculated using the Davies Equation for single ions [8]. The corresponding solubility product is then:

$\mathrm{k}_{1}=\left[\mathrm{Ca}^{2+}\right]\left[\mathrm{OH}^{-}\right]^{2}=2.70 \cdot 10^{-5}$

If excess of a solid phase is in equilibrium with the solution, the total amount of that compound in solution is called the molar solubility, denoted by $\mathrm{S}$ [8]. In a solution that contains $\mathrm{Ca}(\mathrm{OH})_{2}$, the molar solubility is denoted $\mathrm{S}_{\mathrm{CH}}$.

In a saturated solution of an ionic salt, addition of another, more soluble salt containing one of those ions, will decrease the solubility of the first. This is known as the "common-ion effect". The $\left[\mathrm{OH}^{-}\right]$ions in solution originates both from the dissolution of $\mathrm{Ca}(\mathrm{OH})_{2}$ and from the 
amount of alkali released into the porewater. As long as solid $\mathrm{CH}$ is present the following relations should hold:

$\left[\mathrm{Ca}^{2+}\right]=\mathrm{S}_{\mathrm{CH}}$

$\left[\mathrm{OH}^{-}\right]=2 \cdot \mathrm{S}_{\mathrm{CH}}+\left[\mathrm{Na}^{+}\right]$

Substituting Eqs. (6) and (7) into the solubility product $\mathrm{k}_{1}$ (Eq. (5)) gives the following equation:

$\mathrm{k}_{\mathrm{CH}}=\left[\mathrm{Ca}^{2+}\right] \cdot\left(2\left[\mathrm{Ca}^{2+}\right]+\left[\mathrm{Na}^{+}\right]\right)^{2}=4\left[\mathrm{Ca}^{2+}\right]^{3}+4\left[\mathrm{Na}^{+}\right]\left[\mathrm{Ca}^{2+}\right]^{2}+\left[\mathrm{Na}^{+}\right]^{2}\left[\mathrm{Ca}^{2+}\right]$

For a known alkali concentration this equation is dependent in $\left[\mathrm{Ca}^{2+}\right]$ only and was solved analytically using the computer program MATHEMATICA® [9]:

$$
\begin{aligned}
& {\left[\mathrm{Ca}^{2+}\right]=\frac{\left(\left[N a^{+}\right]-X\right)^{2}}{6 \cdot X}} \\
& X=\sqrt[3]{\left(\left[N a^{+}\right]^{3}+27 \cdot k_{C H}+3 \sqrt{3} \cdot \sqrt{k_{C H}} \cdot \sqrt{2 \cdot\left[N a^{+}\right]^{3}+27 \cdot k_{C H}}\right)}
\end{aligned}
$$

When $\left[\mathrm{Ca}^{2+}\right]$ is calculated, $\left[\mathrm{OH}^{-}\right]$can be calculated from the solubility product and the $\mathrm{pH}$ can be determined from the relation $\mathrm{pH}=14+\log \left[\mathrm{OH}^{-}\right]$.

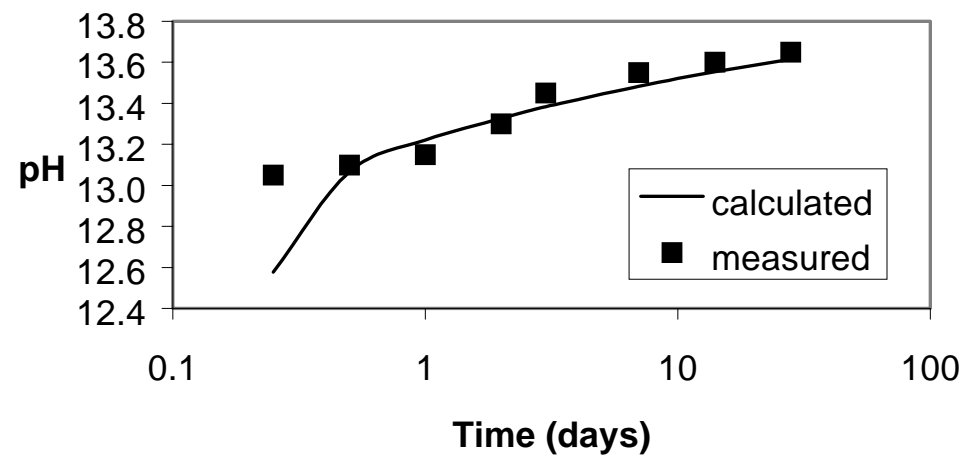

Figure 1. Porewater pH development

Figure 1 shows the calculated $\mathrm{pH}$ development compared with experiments by Pietersen [10]. As can be seen from this figure there is a good agreement from 1 to 28 days of hydration. The disagreement during the first hours of hydration can be explained by the observed supersaturation of $\mathrm{CH}$ [5]. This was not accounted for in the calculations. 


\section{THE PRINCIPLE OF COATING LAYERS}

It is assumed that as soon as cement and water containing the contaminant are mixed, precipitation will occur. According to the chemical equilibria an amount of precipitated product will be formed and this amount or volume will coat the unhydrated cement surface. This results in part of the cement surface being inaccessible for water. Furthermore it is assumed that the precipitated volume is made up of layers of cubic units sized $d_{\text {layer }} 1$

$\mathrm{m} \cdot 1 \mathrm{~m}$. The average number of coating layers present on the initial surface of the cement particles is dependent on the initial amount of precipitated product and can be calculated according to equation (10):

$n_{\text {lavers }}=\frac{\varphi_{p p}^{p}}{d_{\text {layer }} \cdot S A \cdot \rho_{p p}}$

$\mathrm{n}_{\text {layers }}=$ average number of coating layers

$\varphi_{p p}^{p}=$ mass fraction precipitated product precipitated [g/g of cement]

$\mathrm{d}_{\text {layer }}=$ coating layer thickness $[\mathrm{cm}]$

$\mathrm{SA}=$ specific surface area of cement $\left[\mathrm{cm}^{2} / \mathrm{g}\right]$

$\mathrm{pp}=$ precipitated product density

During cement hydration the following mass balance should be obeyed, in which all fractions are in $[\mathrm{g} / \mathrm{g}]$ unreacted cement:

$\varphi_{p p}^{T}=\varphi_{p p}^{s}+\varphi_{p p}^{p}$

$\varphi_{B}^{T}=$ total initial mass fraction precipitated product $[\mathrm{g} / \mathrm{g} \mathrm{OPC}]$

$\varphi_{B}^{s}=$ mass fraction precipitated product (re)dissolved [g/g OPC]

$\varphi_{B}^{T}$ can be calculated from Eq.(11), filling in the theoretical total amount of precipitate in $\left[\mathrm{mole} / \mathrm{dm}^{3}\right]$ that can be formed from the product added, taking into account possible molar differences, and concentration factor $=1 . \varphi_{B}^{s}$ is calculated from the equilibrium concentration of precipitate that is determined after each hydration cycle.

$\varphi_{p p}^{p}=\frac{m_{p p}^{p}}{m_{c}}=\frac{[p p] \cdot w / c \cdot \frac{\varphi_{p o r}}{\varphi_{p o r}^{0}} \cdot M_{p p}}{\rho_{w}}$

$\mathrm{m}_{\mathrm{B}}^{\mathrm{p}}=$ mass precipitated product $[\mathrm{g}]$

$\mathrm{m}_{\mathrm{c}}=$ mass cement $[\mathrm{g}]$

$[\mathrm{pp}]=$ amount of precipitated product $\left[\mathrm{mole} / \mathrm{dm}^{3}\right]$ 
$\frac{\phi_{p o r}}{\phi_{p o r}^{0}}=$ concentration factor (ratio actual porosity to initial porosity)

$\mathrm{M}_{\mathrm{pp}}=$ molecular mass precipitated product [g/mole $]$

${ }_{\mathrm{w}}=$ density water $\left[\mathrm{g} / \mathrm{dm}^{3}\right]$

When the total volume of precipitate is known, it has to be placed at the water exposed surface of the unhydrated cement particles. In the hydration model, the smallest size unit is 1

$\mathrm{m}^{3}$ and the water exposed surface consists of $m_{s}$ surface planes of $1 \mathrm{~m}^{2}$. Then the total volume of precipitate consists of $n$ units of volume $d_{\text {layer }}$ times $1 \mathrm{~m}^{2}$ that have to be placed randomly on the cement particle surface. Subsequently, from statistics [11] one can compute the surface fraction $\mathrm{p}(\mathrm{x})$ that is coated by $\mathrm{x}$ units after placing the total of $\mathrm{n}$ units. The probability $\mathrm{p}$ that one unit is placed on one specific surface plane is inversely proportional to the number of surface planes $\mathrm{m}_{\mathrm{s}}$, so $\mathrm{p}=1 / \mathrm{m}_{\mathrm{s}}$. The surface fraction that remains uncoated, denoted as $\mathrm{p}(0)$ can be calculated as follows:

$\mathrm{p}(0)=\left(1-1 / \mathrm{m}_{\mathrm{s}}\right)^{\mathrm{n}}$

Note that taking a surface of $\mathrm{m}_{\mathrm{s}}=100$ and taking the corresponding total number of units $\mathrm{n}$ as $100 \cdot \mathrm{n}_{\text {layers }}$ is sufficient to produce accurate results for the probabilities of interest. From equation (13) it follows that when the cement surface could be coated by more than 5 coating layers on average, and using the probabilistic placement procedure proposed here, the percentage of uncoated surface decreases to less than $1 \%$. From preliminary simulations it followed that reasonable hydration rates take place when $5 \%$ of the surface is uncoated, corresponding with a probabilistic distribution of 3 coating layers in average.

\section{COMPUTATIONAL RESULTS}

As an example the well-known retarding effects of borates will be described according to the model developed in this work. Calcium diborate $\mathrm{Ca}\left[\mathrm{B}(\mathrm{OH})_{4}\right]_{2} \cdot 2 \mathrm{H}_{2} \mathrm{O}(\mathrm{CBH} 6$ in cement chemistry notation) is formed instantaneously after mixing cement and borate containing water, as a result of the high $\mathrm{pH}$ and high calcium concentration in the porewater. When boric acid $\left(\mathrm{H}_{3} \mathrm{BO}_{3}\right)$ is dissolved in the porewater, it forms $\left[\mathrm{B}(\mathrm{OH})_{4}{ }^{-}\right]$ions and in the presence of $\mathrm{Ca}^{2+}$, the equilibrium of interest is the following [12]:

$\mathrm{Ca}\left[\mathrm{B}(\mathrm{OH})_{4}\right]_{2}(\mathrm{~s}) \Leftrightarrow \mathrm{Ca}^{2+}+2\left[\mathrm{~B}(\mathrm{OH})_{4}{ }^{-}\right]$

$\mathrm{k}_{2}=\left[\mathrm{Ca}^{2+}\right]\left[\mathrm{B}(\mathrm{OH})_{4}\right]^{2}=1.62 \cdot 10^{-6}\left[\mathrm{~mol}^{3} / \mathrm{dm}^{3}\right]$

Defining $\mathrm{S}_{\mathrm{CH}}$ and $\mathrm{S}_{\mathrm{CBH}}$ as the molar solubilities of $\mathrm{CH}$ and $\mathrm{CBH6}$ respectively, yields the following concentration balances:

$\left[\mathrm{B}(\mathrm{OH})_{4}{ }^{-}\right]=2 \cdot \mathrm{S}_{\mathrm{CBH} 6}$ 
$\left[\mathrm{Ca}^{2+}\right]=\mathrm{S}_{\mathrm{CH}}+\mathrm{S}_{\mathrm{CBH} 6}$

From rearranging both equilibria (5) and (15) and all relevant concentration balances and substituting the results back in equation (5), yields the following equation in which $\left[\mathrm{B}(\mathrm{OH})_{4}{ }^{-}\right]$ is the only variable in case $\left[\mathrm{Na}^{+}\right]$is known:

$k_{2}=\left(S_{C H}+S_{C B H 6}\right) \cdot\left[B(O H)_{4}^{-}\right]^{2}=K \cdot\left[B(O H)_{4}^{-}\right]^{3}-\frac{1}{2} \cdot\left[N a^{+}\right] \cdot\left[B(O H)_{4}^{-}\right]^{2}$

$K=\frac{1}{2} \cdot \sqrt{\frac{k_{1}}{k_{2}}}+\frac{1}{2}$

In case of a known alkali concentration the solution of this cubic equation in $\left[\mathrm{B}(\mathrm{OH})_{4}{ }_{4}^{-}\right]$in closed-form is as follows (based on analysis by MATHEMATICA ${ }^{\circledR}[9]$ ):

$$
\begin{aligned}
& {\left[\mathrm{B}(\mathrm{OH})_{4}^{-}\right]=\frac{\left[\mathrm{Na}^{+}\right]+\mathrm{X}}{6 \cdot \mathrm{K}}+\frac{\left[\mathrm{Na}^{+}\right]^{2}}{6 \cdot \mathrm{K} \cdot \mathrm{X}}} \\
& X=\sqrt[3]{\left(\left[\mathrm{Na}^{+}\right]^{3}+108 \cdot k_{2} \cdot K^{2}+6 \sqrt{6} \cdot \sqrt{k_{2}} \cdot K \cdot \sqrt{[N a+]^{3}+54 \cdot k_{2} \cdot K^{2}}\right)}
\end{aligned}
$$

When $\left[\mathrm{B}(\mathrm{OH})_{4}^{-}\right]$is determined, $\left[\mathrm{Ca}^{2+}\right]$ can be calculated according to the ion product $\mathrm{k}_{2}$ and $\left[\mathrm{OH}^{-}\right]$can be calculated using the ion product $\mathrm{k}_{1}$.

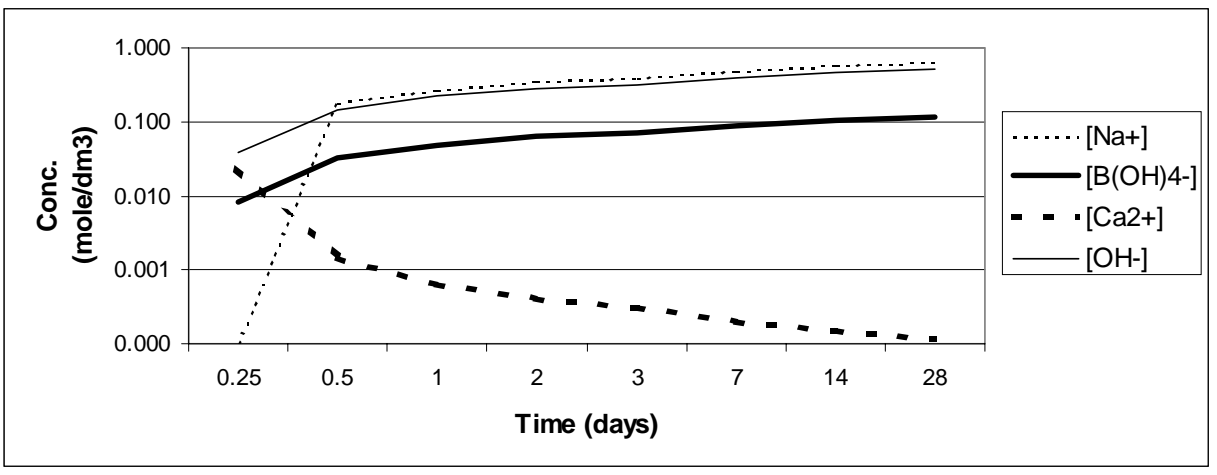

Figure 2. $\left[\mathrm{Na}^{+}\right],\left[\mathrm{B}(\mathrm{OH})_{4}^{-}\right],\left[\mathrm{Ca}^{2+}\right]$ and $\left[\mathrm{OH}^{-}\right]$plotted against time.

In Figure 2, the development of porewater concentrations during undisturbed hydration is plotted against time. When hydration starts, $\left[\mathrm{Ca}^{2+}\right]$ is high and $\left[\mathrm{B}(\mathrm{OH})_{4}{ }^{-}\right]$must be low because of its ion product and $\mathrm{CBH} 6$ precipitates. Then alkalis are released by cement and $\left[\mathrm{Na}^{+}\right]$and correspondingly $\left[\mathrm{OH}^{-}\right]$in the porewater increase. This results in a decrease in $\left[\mathrm{Ca}^{2+}\right]$ because of the $\mathrm{CH}$ ion product. As a result of this $\mathrm{CBH} 6$ can redissolve, the surface coating percentage decreases, hydration rate will increase and more alkali are released. This is a self-accelerating process. From these equilibria it is also clear that when coating percentages 
approach $100 \%$, the hydration rate is too slow to release sufficient alkalis for redissolution of the coating compound. In that case hydration is completely stopped.

From experiments by Lieber and Richartz [13] it is known that hydration can finally proceed, even when pollutant additions up to 1 mass $\%$ are used. Assuming that the crystal layer thickness $d_{\text {crystal }}$ is equal to the unit cell size of the CBH6 crystal (about $6 \cdot 10^{-10} \mathrm{~m}$ ), this addition would correspond with 39 coating layers. According to equation (21), this corresponds with a completely coated surface and hydration would be stopped completely. From this observation it is assumed that the minimum precipitation layer thickness $d_{\text {layer }}$ is build up from a number of crystal layers $\left(\mathrm{n}_{\text {crystal }}\right)$ with the size of one crystal unit of CBH6 $\left(\mathrm{n}_{\text {crystal }}\right)$, so $\mathrm{d}_{\text {layer }}=\mathrm{n}_{\text {crystal }} \cdot \mathrm{d}_{\text {crystal }}$.

The equilibria and coating mechanism described above were implemented in the cement hydration model. When concentrations are calculated during cement hydration it is assumed there is an equilibrium at the end of every hydration cycle. All parameters were chosen according to the experimental conditions used by Lieber and Richartz [13], who examined the effect of boric acid on setting properties and strength development of Portland cement. They used OPC with a SA of $4080\left[\mathrm{~cm}^{2} / \mathrm{g}\right]$, a $\mathrm{Na}_{\mathrm{eq}}$ of $0.92 \%$, a w/c ratio of 0.5 and borate concentrations of up to 1 mass $\%\left(\mathrm{~g} \mathrm{H}_{3} \mathrm{BO}_{3}\right.$ per $\mathrm{g}$ OPC). $\mathrm{n}_{\text {crystal }}$ was estimated as 13 , so that the $1 \%$ addition corresponded with 3 coating layers in average.

Before cement hydration starts, the total initial $\left[\mathrm{B}(\mathrm{OH})_{4}^{-}\right]$and ${ }_{\mathrm{B}}^{\mathrm{p}}$ at $\left[\mathrm{Na}^{+}\right]=0$ is calculated. A digital initial cement microstructure is generated and the cement particle surface is coated according to the probabilistic placement procedure. After performing this procedure, only the uncoated surface planes are initially available for dissolution and reaction.

After each hydration cycle, the $\alpha$ and actual porosity of the cement paste is given by the cement hydration computer model and all parameters of interest can be calculated in the order, $\left[\mathrm{Na}^{+}\right],\left[\mathrm{B}(\mathrm{OH})_{4}{ }^{-}\right],{ }_{\mathrm{B}}^{\mathrm{s}}$ and ${ }_{\mathrm{B}}^{\mathrm{p}}$. According to this recalculated ${ }_{\mathrm{B}}^{\mathrm{p}}$, a corresponding removement of coating from the cement surface is performed. This is done by randomly decreasing the number of coating units from surface planes that are coated by 1 or more coating units. This adjustment results in an increase in uncoated surface planes, making them available for dissolution in the following hydration cycles. $\mathrm{H}_{3} \mathrm{BO}_{3}$ additions of $1.0,0.5,0.2$ and $0.1 \%$ were used in the simulations and hydration was allowed to proceed to an equivalent hydration time of 28 days.

In Figure 3 the hydration degree is plotted against time and one can see a clear difference between the lower 0.1 and $0.2 \%$ and the two higher 0.5 and $1.0 \%$ pollutant additions. For the higher 1 and $0.5 \%$ additions, initially hydration degrees are significantly lower compared to the blank sample. After two or three days their hydration rates increase, while hydration rate of the blank sample is decreasing. At 28 days there was still precipitate and thus coated surface present in both cases. It can be expected that, while hydration continues, all remaining precipitate will redissolve and final hydration degrees degree will be comparable to the blank sample. For the two lower additions 0.2 and $0.1 \%$, the initial coating percentages were less than 50\%, which results in a much quicker initial hydration rate and redissolution of precipitate compared to the other polluted samples. This results in hydration rates that are comparable to the blank sample. The trends found in the simulations agree qualitatively with 
the experimental results by Lieber and Richartz [13], who measured strength development. Strength was calculated from the hydration degree given by the model using the gel-toporosity principle, calculated as follows [14]:

$$
X=\frac{0.68 \cdot \alpha}{0.32 \cdot \alpha+w / c}
$$

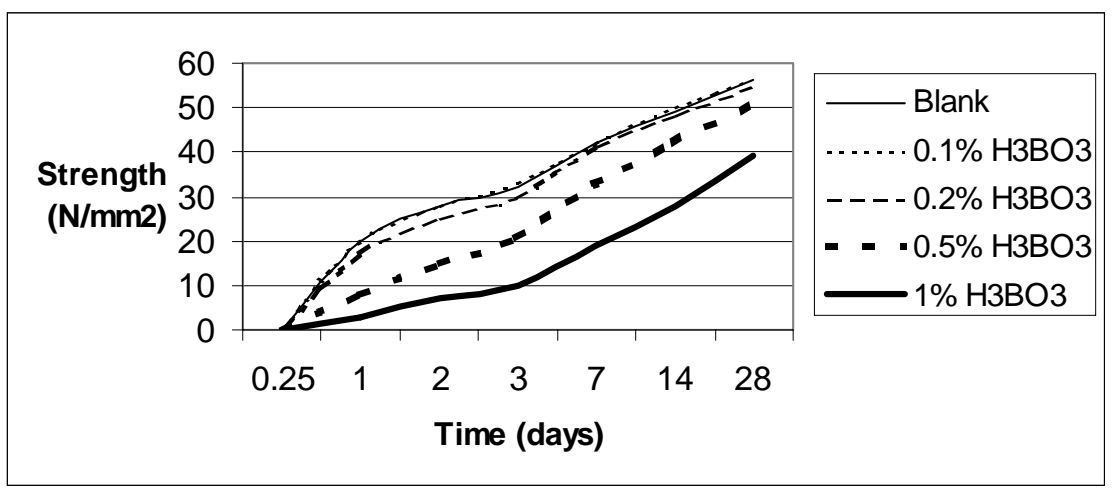

Figure 2: Computed strengths at different pollutant concentrations versus time

For the higher $\mathrm{H}_{3} \mathrm{BO}_{3}$ concentrations added, strength was decreased at ages less than 3 days, but approached blank values after 28 days. The 0.1 and $0.2 \%$ additions showed equal strength development compared to the blank sample. These result agree qualitatively with experimental results from Lieber and Richartz [13].

\section{CONCLUSIONS}

Based on chemical equilibria of calcium salts in the presence of alkalis, quantities of precipitates were computed. It is shown that depending on the hydration degree and related alkali release, calcium salts will precipitate and redissolve. This precipitation model has been incorporated in a numerical cement hydration model and results were compared with experimental data of calcium borates. This yielded good qualitative agreement. An important unknown is the number of crystal layers per coating layer. We have assumed this value to be equal to 13, but this should be validated experimentally. This number is an important parameter that is required for relating used pollutant concentrations and layer thicknesses initially present on the cement surface. The approach presented here can also be used to describe the retarding effects of common pollutants like $\mathrm{Cd}$ and $\mathrm{Zn}$. More research and calculations are required so that in the future hydration in the presence of pollutants can be predicted, taking into account experimental parameters like w/c ratio and specific cement surface area, pollutant concentrations in the mixing water and chemical equilibria of all ions involved. In that case immobilization recipes can be optimized and durability of the solidified product can be predicted. 


\section{REFERENCES}

1. Glasser, F.P., Fundamental aspects of cement solidification and stabilisation, J. Haz. Mat. 52: 151-170 (1997)

2. Yousuf, M. et al., The interfacial chemistry of solidification/stabilization of metals in cement and pozzolanic material systems, Waste Management Vol. 14 No. 2: 137-148 (1995)

3. Diez, J.M., Madrid, J. and Macias, A., Characterization of cement-stabilized Cd wastes, Cem. Concr. res. Vol. 27, No. 3: 337-343 (1997)

4. Bentz, D.P., Three-Dimensional computer simulation of portland cement hydration and microstructure development, J. Am. Ceram. Soc. 80(1): 3-21 (1997)

5. Taylor, H.F.W., Cement chemistry ( $2^{\text {nd }}$ Edition), Thomas Telford, London (1997)

6. B. Batchelor and K. Wu, "Effects of Equilibrium Chemistry on Leaching of Contaminants from Stabilized/Solidified Wastes", in Chemistry and Microstructure of Solidified Waste Forms, R.D. Spence (ed), Lewis Publishers, Boca Raton, Florida (1992).

7. J.D. Allison, D.S. Brown, K.J. Novo-Gradac, "Minteqa2/Prodefa2, A Geochemical Assessment Model for Environmental Systems: Version 3.0 User's Manual", EPA/600/3-91/021, U.S. Environmental Protection Agency, Office of Research and Development, Environmental Research Laboratory, Athens, Georgia (1991).

8. Butler, J.N. (1998), Ionic equilibrium. Solubility and pH calculations, John Wiley \& Sons, New York (1998).

9. S. Wolfram, MATHEMATICA $®\left(2^{\text {nd }}\right.$ Edition $)$, Addison-Wesley Publishing, Redwood City, CA (1991).

10. Pietersen, H.S. Reactivity of fly ash and slag in cement, PhD. Thesis, Delft University of Technology (1993)

11. Feller, W., An introduction to probability theory and its applications, Wiley, N.Y. (1950)

12. Casabonne Masonnave, J.M., Immobilization of borates and phosphate anion with saturated lime solutions, Solid state ionics Vol. 59: 133-139 (1993)

13. Lieber, W. and Richartz, W., Einflu von Triäthanolamin, Zucker und Börsäure auf das Erstarren von Zementen, Zement-Kalk-Gips, 61 (9): 403-409 (1972).

14. Powers, T.C., $4^{\text {th }}$ ISCC, Vol.2 p.577 (1962) 